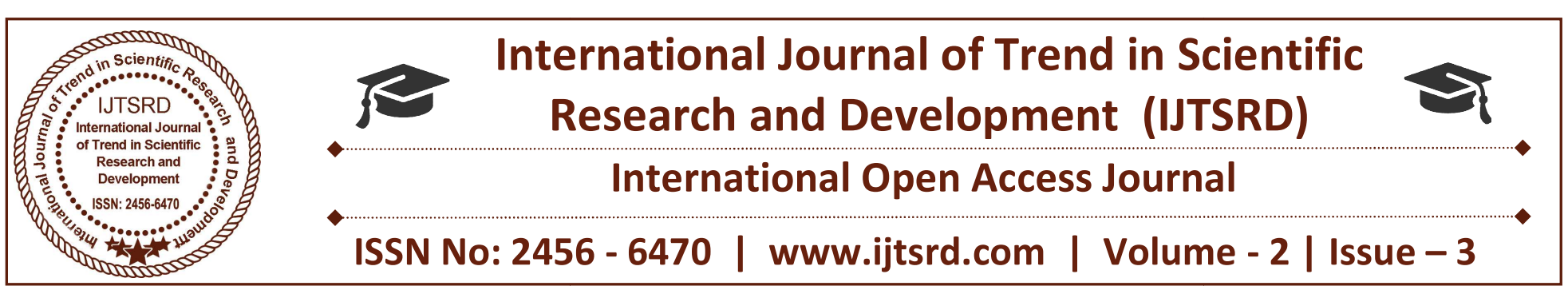

\title{
A Review: Biogas Production from Bakery Waste
}

\author{
Vaibhav Kodag \\ P.G Student, Department of Technology, \\ Shivaji University, Kolhapur, Maharashtra, India
}

\author{
Dr. G. S. Kulkarni \\ Professor, Department of Technology, \\ Shivaji University, Kolhapur, Maharashtra, India
}

\begin{abstract}
The Anaerobic Digestion process is one of the nonthermal technologies of energy recovery from waste. Bakery waste is seen to be a very vital source of nutrient been unused. Bakery waste contains sugars which are easy to degrade along with other nutrients. There is an immense potential of extracting energy from bakery waste in form of biogas. The present paper states that an option of feedstock is available in form of bakery wastes like different varieties of bread, biscuits, rolls, donuts, pizza dough waste etc. underwent experimentations. Bread and biscuit waste for a retention time of 22 to 42 days produced methane $45 \%$ and above. The $\mathrm{pH}$ was found to be in a range of 5.3 to 7.4 for overall bakery waste. The temperature for digestion of these wastes was between $20^{\circ} \mathrm{C}$ to $40^{\circ} \mathrm{C}$.
\end{abstract}

Keywords: Biogas, methane, bakery waste, Anaerobic digestion

\section{INTRODUCTION}

Modern Civilization is based on high energy consumption. On an average, each citizen living on the earth consumes $2 t$ of carbon in a year for energy needs [1].Looking on to these problems of energy crisis solid waste must be processed for energy recovery. Solid waste generated during bakery materials production if treated by anaerobic digestion provides good results. Anaerobic digestion is a degradation of organic substances by microorganisms in the absence of oxygen. It is considered to be one of the most environmentally friendly, costeffective and commercially viable technology for alternating fossil fuel. There are four steps in anaerobic digestion of organic matters. Firstly, complex organic compounds (i.e. carbohydrates, proteins, fats) are degraded into simple soluble substances (i.e. sugars, short chain peptides, amino acids, long chain fatty acids) by hydrolytic bacteria. Secondly, acidogenic bacteria transform these soluble substances into organic acids (i.e. formate, acetate, propionate, and butyrate) including alcohols, ketones, aldehydes, carbon dioxide, hydrogen, ammonia, hydrogen, and water. Thirdly, acetogenic bacteria convert these soluble organic matters into volatile fatty acids (VFAs) comprising mainly acetic acid $(\mathrm{CH} 3 \mathrm{COOH})$ as well as $\mathrm{CO} 2, \mathrm{H} 2$ and so on [3].Thermal technologies like incineration, pyrolysis, gasification etc. provide energy from waste but at the cost of air pollution. In India, because of unavailability of sufficient crude oil and to fulfill the need to energy at domestic as well as an industrial sector, there is an urgent need to find the alternative, eco-friendly source of energy [6]. Anaerobic digestion has been found to be a better option than those thermal technologies for all type of waste including bakery waste. Each bakery producing bread and cakes is a manufacturer of wastes. As a result of the production activity in bakeries, waste are produced such as raw materials and products unsuitable for consumption or processing and unfit for use fats [7]. In evaluating national development and the standard of living of any nation, the supply and consumption of energy are very important. Sustainable resource management of waste and development of alternative energy source are the present challenges due to economic growth [10]. Hence considering one of the sectors for energy recovery in the food industry like bakery which is a source of nutrients and could be utilized for 
digestion. Much solid waste is generated during the production of confectioneries like biscuits and chocolate. The solid waste collected from mixing and packing units are rich in carbohydrates and fats which are easily biodegradable and thus should be a good substrate for biogas production [14].

\section{LITERATURE REVIEW}

VilisDubrovskis et.al. (2017) [1] stated the results of investigated biogas potential from five different damaged bread. About sixteen 0.75 liter bioreactors were pervaded with inoculums or with inoculums combined together with various bread mass. Anaerobic digestion was subjected to a batch mode at a temperature of $38^{\circ} \mathrm{C}$. The results were obtained after a time of 30 days, methane generated was represented in percentage The following specific gas volumes (methane percentage in biogas) were obtained after 30 days anaerobic digestion process: French bread gave about 0.723 1.g-1DOM (50.6\%); whereas Rye flour bread produced 0.634 1.g-1DOM (49.9\%); while Wheat flour(coarse) bread $0.731 \mathrm{l.g}$ 1DOM (50.9\%); and Toaster bread 0.694 l.g-1DOM (44.9\%); White bread (with the addition of egg and milk additives) 0.943 1.g-1DOM (45.4\%). The results showed that damaged bread can be used for biogas production successfully.

Rebecca Hamilton et.al. (2017) [2]stated found that biogas digester has reduced the energy costs by producing biogas and found that a bakery could be feasible, but an in-depth market analysis should be conducted. This analysis was done by constructing biodigester system.

KanchaiSingharat et.al (2017) [3] has explained that Biogas production from bakery wastewater was studied using a semi-continuous, two-stage anaerobic digestion system, consisting of 21 -first-stage digester and 51 -second-stage digester under the temperature of $35{ }^{\circ} \mathrm{C}$. Substrate feed rates were examined in a batch experiment by varying in the range of 50 to $200 \mathrm{ml} / \mathrm{l} / \mathrm{d}$. Characteristics of substrate and effluent of the digester (i.e. pH, SS, TS, VS, VFAs, COD, sCOD, TN, TP, total sulfate), biogas yields and compositions were investigated. The experimental results showed that substrate feed rate of $100 \mathrm{ml} / \mathrm{l} / \mathrm{d}$ produced the maximum yield of biogas. The biogas yield was directly proportional to the concentration of VFAs in the second-stage digester. The approximate $\mathrm{pH}$ values in the first stage and the second stage digesters were 6.13 and 7.25 , respectively. The average biogas yield of $0.481 \mathrm{l} / \mathrm{g}$ VS removed and $0.609 \mathrm{l} / \mathrm{g}$ sCOD removed was observed at a hydraulic retention time (HRT) of 10 days. Biogas contained 46.4\%-60.8\% methane. Removal efficiencies of SS, VS, COD, and SCOD in this system were $85.58 \%, 93.35 \%, 87.91 \%$ and $75 \%$, respectively. The amounts of total nitrogen and total phosphorus after digestion increased whereas that of sulfate decreased.

J K Evicks (2016) [4] stated that this research intends to supplement small data available for using bakery waste in the AD process. The pizza dough was used as a primary feedstock in this study to evaluate the potential through Food to Mass (F/M) ratios. The best $\mathrm{F} / \mathrm{M}$ ratio for this process considering feed rate, COD removal, and gas production were determined to be $0.5 \mathrm{~g} \mathrm{COD} / \mathrm{g}$ VS. Although this product does perform well in the AD process, current market rates for waste disposal in Oklahoma would not support the construction of an industrial scale digester. This work could be expanded in the future by further evaluation of bakery feedstock, a potential for beneficial co-digestion, methane analysis or further specific financial analysis.

KaterinaChamradova et.al. (2015) [5] stated by A laboratory experiment of two-stage mesophilic, lowdry mass, anaerobic digestion was carried out, focused on verifying the benefit of processing the biscuit meal EKPO-EB instead of triticale silage Agostino (GPS) and corn silage LG3266 in a regular batch for the agricultural biogas station in Pustějov. While anaerobic digestion of ensilages is largely difficult due to the content of lignocellulose, biscuit meal provides a high yield of biogas or methane, respectively, thanks to its high content of simple saccharides and lipids. At the initial stage the GPS showed $0.81 \%$ weight of every days input blends/mix amount. Better acceptable results were seen in first stage which shown an increase in volume of methane of about $20 \%$. The feedstock (Biscuit meal EKPO-EB) was fully decomposed by micro organisms at 1 st stage and an increment of volume of methane was seen upto $54 \%$ in initial(first) stage and $16 \%$ in later(second) stage for 
a rise $1.63 \%$ weight of the feed dose provided on every day basis.

ChandratreSangitaJ et.al. (2015) [6] has carried an experiment by designing a small laboratory scale digester unit and using agricultural waste like black gram stalk, Groundnut shells, Soybean straw, Wheat stalk, Red grams straw as feedstock. The current work is an endeavor to study on the chemical analysis of agricultural waste with respect to its different parameters for biogas generation to make an active feedstock. The paper also highlights the general presentation for design a small scale biogas unit intended to be used for further analysis of screened materials for biogas production.

Wioleta KOT et.al. (2015) [7] stated in their article that the results of laboratory tests of the suitability of the baking industry waste such as wheat roll, wheat bread, and a donut, as a substrate for biogas production. The study used the eudiometric stand, located at Chemical Analysis Laboratory of the Institute of Engineering Biosystems UP in Poznan. The experiment was conducted in accordance with DIN 38414 S8. It was found that the wastes containing bread waste showed good performance in case of periodic mixing and reduced process temperature. Waste-based on stale bread can be successfully used for methane fermentation process.

LetaDeressa et.al. (2015) [8] revealed from their research that the anaerobic digestion of fruit and vegetable waste mixed with different waste took 55 days to produce biogas (for complete digestion). It is important to maintain $\mathrm{pH}$ of 6.7-7.4 for a healthy system. Fruit,vegetable waste and cow manure gives optimum yield of biogas and it is found that addition of extra nutrients is not essential if all the parameters are under limits.

Morris E Demitry et.al. (2015) [9] stated that BW is an easily biodegradable substrate for creating a favorable microorganism growth environment, which enhances the biogas production needed for wastewater facilities. It is found that newly created ADM1 model performed well and deviations in parameters like $\mathrm{pH}$, volatile fatty acids (VFA), propionic acid and methane gas production were checked. The output results of the model were compared with experimental batch reactor results of actual BW addition percentages in order to authenticate the model. Stability of the digestion process was achieved until the ratio range of $37-40 \%$ BW: $60-63 \% \mathrm{MS}$, and the digestion processes were inhibited at higher ratios of BW. This research gives an alternative to BW management through utilizing the $\mathrm{BW}$ to increase methane production.

Ukpai, P.A et.al. (2012) [10] has studied by constructing a 45 liters metallic prototype biogas plant at NCERD, University of Nigeria that the anaerobic digestion in generating biogas from three types of wastes: Cow dung, Cowpea, and cassava peeling. The research experiment was batch operated and daily gas output from the plant was supervised for 30 days. The waste to water ratio of following proportions were feed into the digester, 1:2, 1:5, and 1:5 respectively. The mesophilic ambient temperatures range attained within the testing period were $20^{\circ} \mathrm{C}-32^{\circ} \mathrm{C}$ and slurry temperature range $22^{\circ} \mathrm{C}$ $36^{\circ} \mathrm{C}$. The results obtained showed that cowpea produced the highest methane content of $76.2 \%$ followed by cow dung with $67.9 \%$ content and cassava peeling with lowest of $51.4 \%$ of methane. The highest cumulative biogas output of 124.3 L/Total mass of slurry (TMS) was observed from cow dung whereas cowpea generated 87.5 L/TMS and cassava peeling with $87.1 \mathrm{~L} / \mathrm{TMS}$ for 30 days retention time.

S. Potivichayanon et.al. (2011) [11] stated that Production of biogas from bakery waste was enhanced by an additional bacterial cell. This study was divided into 2 steps. A first step, grease waste from bakery industry's grease trap was initially degraded by Pseudomonas aeruginosa. The byproduct concentration, especially glycerol, was determined and found that glycerol concentration enhanced from $12.83 \%$ to $48.10 \%$. Secondary step, 3 bio-digesters were set up in 3 different substrates: non-degraded waste as the substrate in the first biodigester, degraded waste as a substrate in the secondary bio-digester, and decomposed waste mixed with swine manure in ratio $1: 1$ as a substrate in the third bio-digester. The highest concentration of biogas was found in third bio digester that was $44.33 \%$ of methane and $63.71 \%$ of carbon dioxide. During anaerobic digestion of stage 2 digester it was found that methane and carbondioxide was about $24.9 \%$ and $18.98 \%$ respectively.. Whereas the least 
was found in the non-degraded waste bio-digester. It was demonstrated that the biogas production was greatly increased with the initial grease waste degradation by Pseudomonas aeruginosa.

J.B. Holm-Nielsen et.al. (2009) [12]found in their analysis that large magnitude of solid waste always coexists with the production of a excess of animal manure, representing a rise in pollution dangers to the ecology in the vicinity areas . Avoiding overfertilization is not only important for environmental protection reasons but also for economic reasons. The waste generated from animals is highly organic and huge quantities of waste requires a proper utilization of waste as a resources for recovery of energy and economy. Anaerobic digestion of animal manure and slurries offers several benefits by improving their fertilizer qualities, reducing odors and pathogens and producing a renewable fuel - the biogas. The EU policies regarding renewable energy systems (RES) have set a firm baseline goal of supplying $20 \%$ of the European energy demands from RES by the year 2020. A major part of the renewable energy will originate from European farming and forestry. In further coming years Biogas/ Bioenergy can provide about $25 \%$ of energy from overall organic materials like animal manure, whole crop silages, food waste etc.

J. Paul Chen et.al. (2006) [13] has discussed various bakery waste and water sources, their characteristics, different types of treatment systems available and suitable for bakery waste and cater the preventive measures to be followed for reducing waste and increasing cost-saving benefits.

D.R.Ranade et.al. (1989) [14] found that Chocolate and biscuit waste contains sugars as a common and in great proportions and its degradation by anaerobes provides better results hence a 180-liter capacity biogas plant of floating dome type was designed. Three different hydraulic retention times (HRT) viz.20, 30 and 40 days were studied with $10 \%$ total solids in the influent slurry. The data collected showed that waste is amenable to anaerobic digestion. After the Anaerobic digestion process, the results obtained stated that biogas produced was more at 40 days $\mathrm{HRT}$, viz.466 liters $\mathrm{kg}-1$ waste added per day with $57 \%$ methane and $65 \%$ degradation in volatile solids. The anaerobic digestion at lower HRT, viz 20 and 30 days, resulted in high VFA concentration and low $\mathrm{PH}$ of the fermenting slurry.

\section{DISCUSSION}

From the study of all above literature, it is understood that anaerobic digestion of bakery waste occurs at a temperature ranging from $20^{\circ} \mathrm{C}$ to $40^{\circ} \mathrm{C}$ i.e. in mesophilic conditions. The retention time for decomposition of Bakery waste (BW) is found to be ranging from 12 to 55 days. $\mathrm{PH}$ is found to be varying from 5.3 to 7.4 and methane content in the biogas was about $45 \%$ and above depending upon the quantity of feedstock. BW contains sugars, carbohydrates as a major constituent and others nutrients with minor proportions since sugars are very easily degraded by microorganisms and also bakery waste is a source of rich nutrient it could be used for biogas production. Co-digestion of BW with other organic materials like Municipal sludge(MS), Fruit and vegetable waste, agricultural waste etc. could be a better option for biogas generation as an increase in methane production was observed with the addition of BW. The bakery waste materials like bread (wheat, French, rye flour, toaster, milk etc.), biscuits, a donut with jam, pizza dough etc. produced biogas with positive results. Bakery wastewater also gave biogas production as that of solid waste bakery materials since it contains nutrients and organic matter in dissolved/ suspended state. Also, a study came across which stated that Sulphur free hydrogen and methane from bread waste are also generated in Japan by controlling fermentation process [15]. Recently a Company named Enki Energy has developed a small-scale anaerobic digester which operates on waste bread and produces biogas. Their plant is operational at Amsterdam [16].

\section{CONCLUSION}

The study has concluded that anaerobic digestion has proved to be a suitable option for energy recovery from bakery waste as it is a clean method and produces more than $45 \%$ of methane in biogas. Bakery waste is a food waste containing rich nutrients and as that of the various bakery waste mentioned in the paper, it has proved to be useful in biogas production. Further many other types of bakery waste items should be analyzed and must demarcate the way for heavy, medium and small 
bakery industries to utilize the waste and thus save cost and energy. Similarly one can run a small biogas at a household level and as the paper suggests using bakery waste along with kitchen waste or house backyard waste as a feedstock for biogas extraction is possible.

\section{REFERENCES}

1. VilisDubrovskis, Imants Plume, "Biogas Potential from Damaged Bread", Engineering for Rural Development, 2017, pp.437-442.

2. Rebecca Hamilton, Zachary Ligham, Connor Willgress, Jingyi Wu, " Bakery and Biodigester in Paraguay", Increasing sustainability of the La Escuela Agricola San Fransisco, Worcester Polytechnic Institute 2017, pp.1-37.

3. KanchaiSingharat, SiriratSangkarak, OnumaPongsuk and Suwannee Junyapoon, "Biogas Production from Bakery wastewater in Two-Stage Anaerobic Digestion System", "KMITL Sci. Tech. Journal", Vol.17 No.1 JanJun.2017, pp.103-112.

4. J K Evicks, "Bakery Waste as a Feedstock to Anaerobic Digestion", Report for the degree of Master of Science, Oklahoma State University, 2016, pp. 1-67.

5. KaterinaChamradova, Jiri Rusin, "Use of biogas biscuit meal EKPO-EB for agricultural biogas plant for substitution of energy crops utilization with organic wastes", "Polish Journal of Chemical Technology", Vol. 17, No. 3, 2015, pp. 40-46.

6. ChandratreSangita J, Chaudhari Vishal, KulkarniBhushan, MahajanBhushan and BavaskarKaustubh P, " Biogas production from Local Agricultural waste by using Laboratory Scale Digester", "Research Journal of Recent Sciences", Vol.4(IYSC-2015), pp. 157-165.

7. Wioleta KOT, Mariusz ADAMSKI, Karol DURCZAK, "USEFULNESS OF THE BAKERY INDUSTRY WEST FOR BIOGAS PRODUCTION", "Journal of Research and Applications in Agricultural Engineering" 2015, Vol. 60(2), pp. 43-45.
8. LetaDeressa, Solomon Libsu, R B Chavan, Daniel Manaye, AnbessaDabassa, " Production of Biogas from Fruit and Vegetable Waste Mixed with Different Wastes", " Environment and Ecology Research 3(3)",2015, pp. 65-71.

9. Morris E. Demitry, JianmingZhong, Conly Hansen, Michael McFarland, "Modifying the ADM1 Model to Predict the Operation of an Anaerobic digester Co-digesting of Municipal Sludge with Bakery Waste", "Environment and Pollution", Vol. 4, No. 4; 2015, pp. 38-57.

10. Ukpai P.A and Nnabuchi M.N, " Comparative study of biogas production from cow dung, cow pea and cassava peeling using 45 liters biogas digester", "Advances in Applied Science Research" 2012,3(3), pp. 1864-1869.

11. S. Potivichayanon, T. Sungmon, W. Chaikongmao, and S. Kamvanin, "Enhancement of Biogas Production from Bakery Waste by Pseudomonas aeruginosa", "International Journal of Chemical, Molecular, Nuclear, Materials and Metallurgical Engineering Vol:5, No:8, 2011, pp. 655-658.

12. J.B. Holm-Nielsen, T. Al Seadi, P. OleskowiczPopiel, "The future of anaerobic digestion and biogas utilization", "Bio resource Technology "100 (2009), pp. 5478-5484.

13. J. Paul Chen, Lei Yang, and RenbiBai, Yung-Tse Hung, "Bakery Waste Treatment", (CTaylor \& Francis Group, LLC ,2006, pp. 271-289.

14. D.R. Ranade, T.Y. Yeole, K.K. Meher, R.V. Gadre, S.H. Godbole, "Biogas from Solid Waste Originated during Biscuit and Chocolate Production: A preliminary Study", "Biological Wastes 28", 1989, pp. 157-161.

15. http://www.enki-energy.com/en/broodvergisterkoken-buurtkeuken/

16. http://connection.ebscohost.com/c/articles/16515 305/methane-hydrogen-generated- frombread-waste 